\title{
Management of marine resources; combining industry and research
}

\author{
P.J. MANSELL, D.J. SUGGETT AND D.J. SMITH
}

\begin{abstract}
Modern day conservation requires a research approach that is truly trans-disciplinary to ensure that natural resources are effectively managed from a bottom-up and top-down perspective. Numerous opportunities potentially exist to better manage aspects of the aquaria trade such as coral farming for conservation outcomes, or the utilization of industry data for the optimization of coral growth, thereby enhancing our understanding of environmental regulation of coral productivity. However such collaborations, partnerships and initiatives need to be very carefully and transparently managed for the good of all parties. In particular, the use of an exploitative industry for direct 'in the field' conservation impact is likely to be politically sensitive. It is therefore essential that full knowledge of the biology and ecology of the system as well as all possible system implications of exploitative activities are known and that the conservation benefits of research-industry partnerships are fully communicated to and understood by all stakeholders. These actions will reduce the risk of miscommunication and inadequate socialization of the project; these being the greatest possible threats to any partnership.
\end{abstract}

Considering the ever increasing threat of over-extraction of marine resources it is a priority to implement management strategies which are designed to support the economic requirements as well as the day to day needs of local communities. Without real and achievable alternative livelihood practises being put in place, management initiatives are likely to have limited conservation success. Detailed understanding of the biology of systems along with local and regional socioeconomic characteristics that can all be contextualized within an area's political framework should lead to more pro-active and successful management outcomes (Smith et al., 2007).

Conservationists, fisheries biologists and those involved with the aquaria trade have mutual concerns and aim to ensure, or otherwise require, a productive and biodiverse reef environment; in this sense all parties are inextricably linked. Addressing key research priorities often requires resources outside those available to the research and conservation community but can be readily available within the different industrial sectors. Historically academics and industry

Corresponding author:

D.J. Smith

Email: djsmitc@essex.ac.uk have operated in parallel addressing similar questions but without combining resources, expertise and experiences. Through collaboration and resource sharing it is most likely that the reef community as a whole (herein defined as all stakeholders) will be much better placed to investigate common areas of interest such as active growth, increased fecundity, reduced mortality and enhanced resilience (Forsman et al., 2006; Shafir et al., 2006).

Despite mutual interests and perhaps due to different agendas, pressures and time-scales there has been limited engagement between the different stakeholders although there is a high probability of synergistic outcomes. This Special Issue of the Journal of the Marine Biological Association of the United Kingdom (JMBA) examines aspects of reef and reef resource usage from both a research and industry point of view. The production process of the Issue in itself has led to new relationships between academia and industry and is one way in which synergism can be demonstrated leading to the better understanding of reef processes and key conservation issues. Publications herein have been brought together through the JMBA remit for those readers interested in coral reef ecology, physiology, climate change, reef resource usage, the maritime industry, reef communities, conservation and the aquaria trade.

In the past, opportunities to capitalize on the international standard of coral reef research being undertaken have been limited. Where partnerships were previously formed they tended to be transient and project specific, thus reducing the capacity to enable the identification of new activities and mutually beneficial projects. The Coral Aquarist Research Network (CARN) was launched in 2009 through the Knowledge Exchange Fellowship Programme funded by the Natural Environment Research Council (NERC). CARN was designed as a platform to facilitate direct engagement of coral reef researchers and those involved in coral industries with the research agenda being identified and developed by all associated parties. Evidence of the impact of CARN has been demonstrated in many of the articles published within this Special Issue including those by Crabbe (2012), D'Angelo \& Wiedenmann (2012), Hartle-Mougiou et al. (2012), Hoeksema et al. (2012), Osinga et al. (2012a, b), Schutter et al. (2012) and Sweet et al. (2012); which were all initially presented at the first CARN conference held in June 2010 at the Royal Geographical Society in London.

Conservation management can use a top-down, legal regulatory as well as a bottom-up, participatory approach. Both of 
which require management strategies to be fundamentally based on a clear understanding of system mechanisms such as the drivers of biodiversity and ecosystem stability as well as consequences of disturbance and impacting factors. Detailed understanding and appreciation of biology is therefore key although surprisingly is often considered secondary to other management drivers be they biological, political or economic with much of the biology of reef systems being largely unknown and non-described. Symbiotic interactions are a fundamental part of most biological systems with the subsequent relationships having a major impact on the biodiversity of coral reefs (Hoeksema et al., 2012). Outside of the tropics, rocky coralligenous regions have a large number of taxa co-existing that provide an ideal habitat for rich molluscan assemblages (Urra et al., 2012) and biodiversity rich regions of biogenic reefs in the UK are being protected to preserve the community composition contained within (Chapman et al., 2012). By establishing how 'natural' the responses seen in captivity actually are will provide researchers with vital information that could answer many questions that simply cannot be achieved over a similar timeframe in the field (Hartle-Mougiou et al., 2012) although field studies will occasionally highlight new species or provide additional information to that already known such as that shown in Guzman \& Breedy (2012) and Kleeman \& Baal (2012).

Growth of species, populations and their potential influence on community structure is dependent upon the way in which a species interacts with its physical, chemical and biological environment. Species tend to live within environmental optima. However, as the pressure on our environments increases and diversifies in terms of conditions, the implications for species and communities are wide ranging. We therefore need to gain a better understanding of how environments regulate the growth and fitness of individual species and in turn how these species interact at higher levels of system complexity (Carr et al., 2002). Key to the success of tropical reef systems and therefore primary drivers of biodiversity are the reef building corals. Research has demonstrated that environments greatly regulate rates of growth but also architecture of coral colonies. Changes to architecture have great influences on the associated biodiversity and consequently knowledge of environmentally regulated growth across taxon and bioregions is crucial to understanding the fundamental process of high biodiversity and maintenance of diversity mechanisms. Environmental and climatic disturbances can have significant impacts on our global ecosystems with many factors influencing species growth; by investigating the conditions required to optimize coral growth under laboratory conditions, these benefits can be transferred to the aquaculture industry to improve sustainability (Shutter et al., 2012). A key priority action for field researchers and conservation managers is to enhance the rates of growth and net reef development. Difficulties arise however when trying to identify the key drivers of changing dynamics which can be supported by laboratory-based studies. Enclosed aquaria systems will never provide an exact comparison to the variability of conditions within a field environment; however, the information obtained can strongly enhance studies of the drivers of coral growth.

Improved husbandry of captive corals is the key to a more sustainable coral trade; investigating the optimal feeding regimes for captive corals (Osinga et al., 2012b) or determining the effect of light, food supply and water flow will provide a better insight into the growth of corals in captivity (Kimokeo et al., 2012). Experiments performed in captivity provide opportunities by which conditions can be adapted to simulate future seawater conditions based on climate change and ocean acidification for example (Toonen et al., 2012) and for the fertilization success of corals in areas that have increased turbidity (Erftemeijer et al., 2012). Experiments that examine the influence of varying environmental conditions on coral growth and nutrition will provide insights into the fundamental biology of coral species and their ability to acclimate across a range of conditions. Such responses are likely to be critical in the near future (Crabbe, 2012). These studies can provide experimental study data that can be used to construct and validate models that will enable researchers to examine likely outcomes of changing environments and industry to identify optimal growth conditions. The CORALZOO project has also benefited the aquaria industry immensely by improving the methodologies used to grow and maintain corals kept in captivity. Numerous partners from research, industry and aquaria organizations collaborated in this four year European Union funded project that was completed in 2010 (Osinga et al., 2012a).

Environmental growth conditions may or may not be constrained but what is apparent is that species have to cope with periodic environmental stress events. Many climatic models are predicting an increased occurrence of these events meaning that understanding how species and communities are regulated by environmental conditions is extremely important (Randall et al., 2007). We also need to know how a species' competitive ability is influenced by its stress biology; species that are competitive under optimal conditions may not be the same species that are able to cope and dominate systems when stress events become more frequent (Suggett \& Smith, 2011; Pandolfi et al., 2011; Russell et al., 2011). The ability of a species to acclimate to stress environments is a function of both the genetic footprint and also its environmental growth histories. Consequently the future of marine communities is a combination of this ability to acclimate and the way in which individual components of the system react during such events. New molecular methods and techniques looking at the stress physiology of corals are being tested under strictly controlled conditions at the National Oceanography Centre, Southampton, UK (D'Angelo \& Wiedenmann, 2012). The invasion of warm/tropical marine alien species often associated with warmer water temperatures and subsequent changes in the respective ecosystem has been documented for decades; the relationship between new alien species and global temperatures is discussed in Pancucci-Papadopoulou et al. (2012). Environmental growth also includes disease and consequently research into coral disease has also been on the increase in recent years. Those found naturally in the environment do not translate directly to those in captivity. By determining the relationship between the two could dramatically improve the understanding and benefits of coral husbandry, improve opportunities for coral culture, reduce mortality within a closed system, and reduce environmental impacts on our natural resources (Sweet et al., 2012). Despite its common presence on reefs globally, outbreaks of the starfish Acanthaster planci can occasionally have a major impact on coral reefs. There is still a large amount of research required to provide explanations for the increased recruitment and subsequent outbreaks of these species (Lane, 2012). 
Regardless of the winners and losers and the overall resilience of a system, it is clear that with ever expanding populations and the changes in the utilization of marine resources as a provider of food, income and livelihoods for millions of the world's population, marine resources will always be exploited. Depleted fisheries stock, reduced system diversity, and decreased habitat quality, productivity and functionality are all evidence for the increasing pressures on coral reef resources. Changes to the way in which reef resources are utilized and managed are a top conservation priority and tighter regulation which is embedded in working policy is required. For example, current regulations within many global commercial shrimp fisheries are resulting in exploitation and significant stock reductions. Further assessments are hoping to initiate new fisheries policies aimed at reducing this impact (Paramo \& Saint-Paul, 2012) and these policies must consider the fundamental biology of the system and in particular the population genetics and dynamics (De Croos \& Pálsson, 2012). Another example of changing policies is that seen within some examples of the sea cucumber fishery, by estimating natural mortality rates based on stock reduction and species exploitation (Dissanayake \& Stefansson, 2012). Mass reductions in populations is evident throughout the sector, for example, the yellow eel, Anguilla anguilla with the latest figures showing a reduction in the population to only $1 \%$ of 30 years ago and insufficient recruitment to compensate (Henderson et al., 2012). The direct impacts of commercial fisheries have very much become the centre of discussion over the years along with the controversial subject of indirect impacts such as by-catch of marine life such as turtles. Improvements to the fishing equipment and techniques used as well as awareness campaigns are required to decrease unnecessary and detrimental by-catch (Echwikhi et al., 2012).

In this changing world constant changes and adaptations are being made to the utilization of our depleting natural resources. To date there has been limited engagement between research and industry with limited mechanisms in place to enable, or stimulate, industry to capitalize on the international standard of research being undertaken by academic institutes. By capitalizing on future engagement opportunities and incorporating knowledge exchange with the sharing of responsibilities and expertise, the efforts from all sectors of society can be collaborated in a synergistic manner. This participatory approach will enable key projects to be identified and ensure stakeholder buy-in, participation and willingness. These factors are the basis of successful partnerships, sustainable management and improvement of the conservation of marine systems and their associated marine resources.

\section{REFERENCES}

Carr M.H., Anderson T.W. and Hixon M.A. (2002) Biodiversity, population regulation, and the stability of coral-reef fish communities. Proceedings of the National Academy of Sciences of the United States of America 99, 11241-11245.

Chapman N.D., Moore C.G., Harries D.B. and Lyndon A.R. (2012) The community associated with biogenic reefs formed by the polychaete, Serpula vermicularis. Journal of the Marine Biological Association of the United Kingdom 92, 679-685.
Crabbe M.J.C. (2012) Environmental effects on coral growth and recruitment in the Caribbean. Journal of the Marine Biological Association of the United Kingdom 92, 747-752.

D’Angelo C. and Wiedenmann J. (2012) An experimental mesocosm for long term studies of reef corals. Journal of the Marine Biological Association of the United Kingdom 92, 769-775.

De Croos M.D.S.T. and Pálsson S. (2012) Population biology and genetic diversity of two adjacent shrimp (Parapenaeopsis coromandelica) populations exploited under different fishing pressures in the coastal waters of Sri Lanka. Journal of the Marine Biological Association of the United Kingdom 92, 819-829.

Dissanayake D.C.T. and Stefansson G. (2012) Present status of the commercial sea cucumber fishery off the north-west and east coasts of Sri Lanka. Journal of the Marine Biological Association of the United Kingdom 92, 831-841.

Echwikhi K., Jribi I., Bradai M.N. and Bouain A. (2012) Interactions of loggerhead turtle with bottom longline fishery in the Gulf of Gabès, Tunisia. Journal of the Marine Biological Association of the United Kingdom 92, 853-858.

Erftemeijer P.L.A., Hagedorn M., Laterveer M., Craggs J. and Guest J.R. (2012) Effect of suspended sediment on fertilization success in the scleractinian coral Pectinia lactuca. Journal of the Marine Biological Association of the United Kingdom 92, 741-745.

Forsman Z.H., Rinkevich B. and Hunter C.L. (2006) Investigating fragment size for culturing reef-building corals (Porites lobata and P. compressa) in ex situ nurseries. Aquaculture 261, 89-97.

Forsman Z.H., Kimokeo B.K., Bird C.E., Hunter C.L. and Toonen R.J. (2012) Coral farming: effects of light, water motion and artificial foods. Journal of the Marine Biological Association of the United Kingdom 92, 721-729.

Guzman H.M. and Breedy O. (2012) Pacifigorgia marviva (Anthozoa: Octocorallia): a new species from Coiba National Park, Pacific Panama. Journal of the Marine Biological Association of the United Kingdom 92, 693-698.

Hartle-Mougiou K., D'Angelo C., Smith E.G., Burt J., West P. and Wiedenmann J. (2012) Diversity of zooxanthellae from corals and sea anemones after long-term aquarium culture. Journal of the Marine Biological Association of the United Kingdom 92, 687-691.

Henderson P.A., Plenty S.J., Newton L.C. and Bird D.J. (2012) Evidence for a population collapse of European eel (Anguilla anguilla) in the Bristol Channel. Journal of the Marine Biological Association of the United Kingdom 92, 843-851.

Hoeksema B.W., Van Der Meij S.E.T. and Fransen C.H.J.M. (2012) The mushroom coral as a habitat. Journal of the Marine Biological Association of the United Kingdom 92, 647-663.

Kleeman K. and Baal C. (2012) Note on the coral Blastomussa loyae, a valid species from the Red Sea. Journal of the Marine Biological Association of the United Kingdom 92, 699-702.

Lane D.J.W. (2012) Acanthaster planci impact on coral communities at permanent transect sites on Bruneian reefs, with a regional overview and a critique on outbreak causes. Journal of the Marine Biological Association of the United Kingdom 92, 803-809.

Osinga R., Van Delft S., Lewaru M.W., Janse M. and Verreth J.A.J. (2012b) Determination of prey capture rates in the stony coral Galaxea fascicularis: a critical reconsideration of the clearance rate concept. Journal of the Marine Biological Association of the United Kingdom 92, 713-719.

Osinga R., Schutter M., Wijgerde T., Rinkevich B., Shafir S. and Shpigel M. (2012a) The CORALZOO project: a synopsis of four years of public aquarium science. Journal of the Biological Association of the United Kingdom 92, 753-768. 
Pancucci-Papadopoulou M.A., Raitsos D.E. and Corsini-Foka M. (2012) Biological invasions and climatic warming: implications for south-eastern Aegean ecosystem functioning. Journal of the Marine Biological Association of the United Kingdom 92, 777-789.

Pandolfi J.M., Connolly S.R., Marshall D.J. and Cohen A.L. (2011) Projecting coral reef futures under global warming and ocean acidification. Science $333,418-422$.

Paramo J. and Saint-Paul U. (2012) Deep-sea shrimps Aristaeomorpha foliacea and Pleoticus robustus (Crustacea: Penaeoidea) in the Colombian Caribbean Sea as a new potential fishing resource. Journal of the Marine Biological Association of the United Kingdom 92, $811-818$.

Randall D.A., Wood R.A., Bony S., Colman R., Fichefet T., Fyfe J., Kattsov V., Pitman A., Shukla J., Srinivasan J., Stouffer R.J., Sumi A. and Taylor K.E. (2007) Climate models and their evaluation. In Solomon S., Qin D., Manning M., Chen Z., Marquis M. Averyt K.B., Tignor M. and Miller H.L. (eds) Climate Change 2007: the physical science basis. Contribution of Working Group I to the Fourth Assessment Report of the Intergovernmental Panel on Climate Change. Cambridge, UK and New York, USA: Cambridge University Press.

Russell B.D., Harley C.D.J, Wernberg T., Mieszkowska N., Widdicombe S., Hall-Spencer J.M. and Connell S.D. (2011) Predicting ecosystem shifts requires new approaches that integrate the effects of climate change across entire systems. Biology Letters doi:10.1098/rsbl.2011.0779.

Schutter M., Van Der Ven R., Janse M., Verreth J.A.J., Wijffels R.H. and Osinga R. (2012) Light intensity, photoperiod duration, daily light flux and coral growth of Galaxea fascicularis in an aquarium setting: a matter of photons? Journal of the Marine Biological Association of the United Kingdom 92, 703-712.

Shafir S., Van Rijn J. and Rinkevich B. (2006) Coral nubbins as source material for coral biological research: a prospectus. Aquaculture 259, 444-448.

Smith D.J., Pilgrim S.E. and Cullen L.C. (2007) Coral reefs and people. In Pretty J., Ball A., Benton T., Guivant J., Lee D., Orr D., Pfeffer M. and Ward H. (eds) Sage handbook on environment and society. London: Sage, pp. 1081-1117.

Suggett D.J and Smith D.J. (2011) Interpreting the sign of coral bleaching as friend vs. foe. Global Change Biology 17, 45-55.

Sweet M., Jones R. and Bythell J. (2012) Coral diseases in aquaria and in nature. Journal of the Marine Biological Association of the United Kingdom 92, 791-801.

Toonen R.J., Nakayama T., Ogawa T., Rossiter A. and Delbeek J.C. (2012) Growth of cultured giant clams (Tridacna spp.) in low $\mathrm{pH}$, high-nutrient seawater: species-specific effects of substrate and supplemental feeding under acidification. Journal of the Marine Biological Association of the United Kingdom 92, 731-740.

and

Urra J., Rueda J.L., Gofas S., Marina P. and Salas C. (2012) A speciesrich molluscan assemblage in a coralligenous bottom of the Alboran Sea (south-western Mediterranean): intra-annual changes and ecological considerations. Journal of the Marine Biological Association of the United Kingdom 92, 665-677. 